\title{
The Birmingham trial of the O'Malley light coagulator
}

\author{
V.MYSKA AND K. RUBINSTEIN \\ Birmingham
}

During the months of April and May, 1972, thirty consecutive cases from the Medical @ Ophthalmology Clinic, Birmingham and Midland Eye Hospital, requiring light coagula- $\overrightarrow{0}$

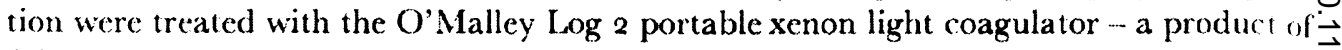
Clinitex Inc., Beverley, Mass. (Figs 1 and 2). The instrument represents the first attempt $\omega_{\mathscr{\omega}}$

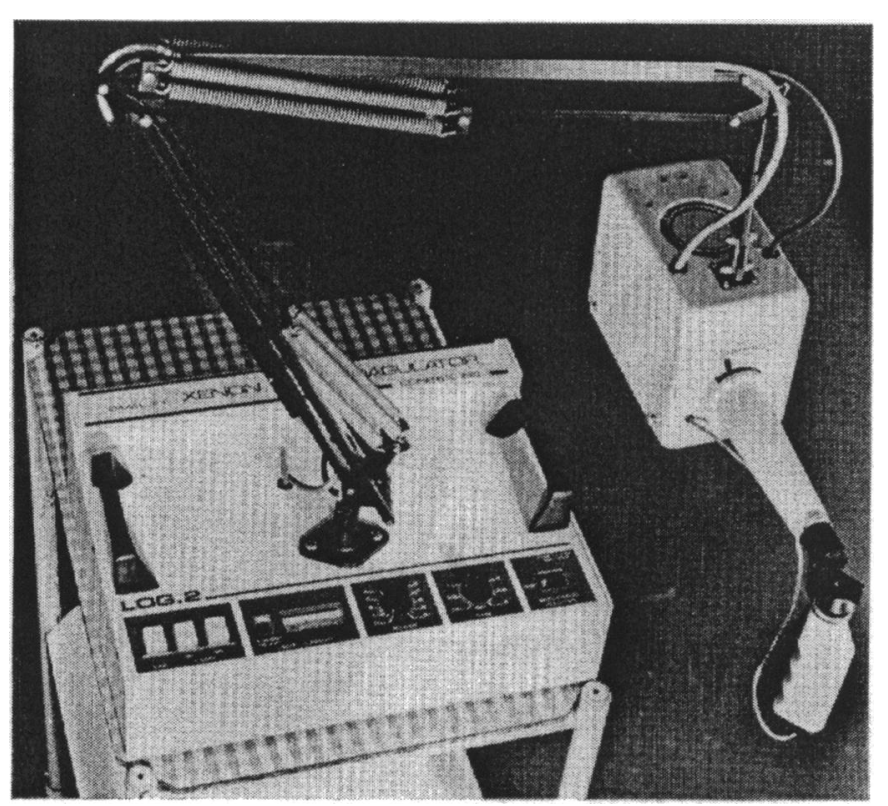

Fia. I O'Malley xenon ligh! coagulator

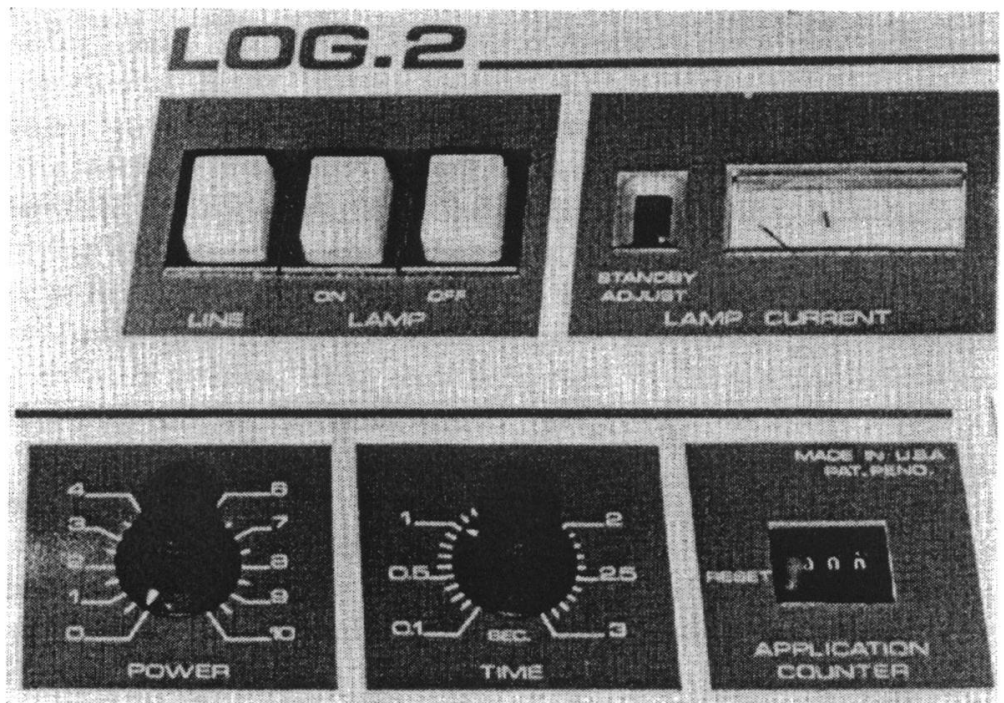

FIci. 2 Control ponel fri. 2 Cionirol phand 
at a long overdue miniaturisation of light coagulation equipment, and in particular an improvement on its manoeuvrability. For the last 20 years the standard equipment used in this hospital has been the Zeiss (Oberkochen) machine, and the new instrument is necessarily compared with this.

\section{Instrument specifications}

(I) Dimension - I $7 \frac{1}{2}^{\prime \prime} \times 14 \frac{1}{2}^{\prime \prime} \times 4^{\prime \prime}$; weight -5 olb.; reach of articulated arm $-41^{\prime \prime}$

(2) The power source is by simple mains connection (I 15 or 220 volts) with built-in voltage regulator. No special electrical installations are necessary

(3) Ophthalmoscope head manoeuvrability achieved by suspension angle-poise fitting and comparable with standard battery direct ophthalmoscope

(4) Aperture sizes $-2^{\circ}, 3^{\circ}, 4^{\circ}, 5^{\circ}$, and $6^{\circ}$

(5) Diameter of light beam in the pupil: maximum $8.5 \mathrm{~mm}$.

(6) Range of power control: I to Io

(7) Pre-selected time controls from $0 \cdot 1$ to 3 secs., allowing continuous precise adjustment

(8) 3-digit application counter

(9) Observation field of $25^{\circ}$ with defined target area.

\section{Glinical material}

The thirty patients treated with the O'Malley light coagulator were affected by diabetic retinopathy ( 19 cases), exudative senile maculopathy (4 cases), circinate retinopathy (3 cases), central serous retinopathy ( 2 cases), malignant melanoma (I case).

In 22 cases the aperture used was $3^{\circ}$; the largest aperture required for sufficient reaction was $6^{\circ}$, and this was in the case of a large peripheral horseshoe tear of the retina. In cases of central serous retinopathy (Fig. 3) and close paramacular applications in diabetic retinopathy (Fig. 4) aperture $2^{\circ}$
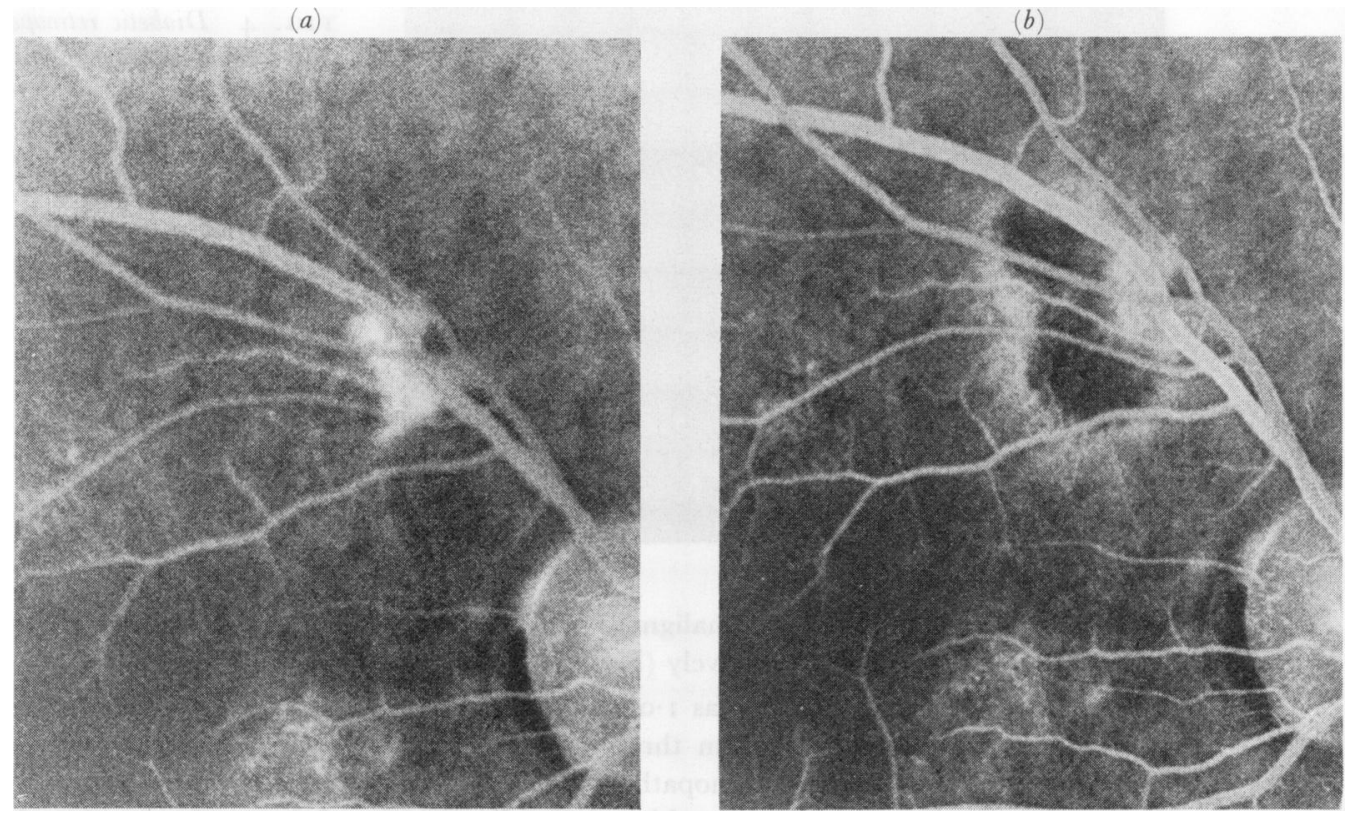

FIG. 3 Fluorogram. Central serous retinopathy with remote leakage source; $(a)$ before, $(b)$ after light coagulation with O'Malley instrument. Aperture $2^{\circ}$, power 5 , exposure $\mathrm{I} \cdot 5 \mathrm{sec}$. 
(a)

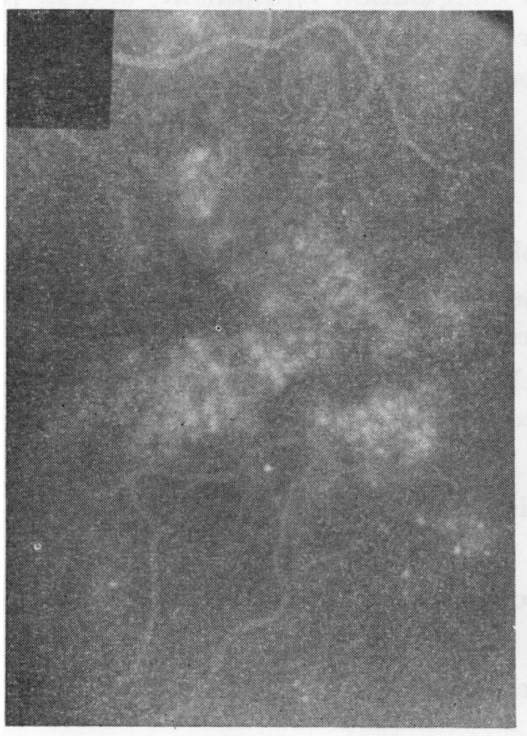

(b)

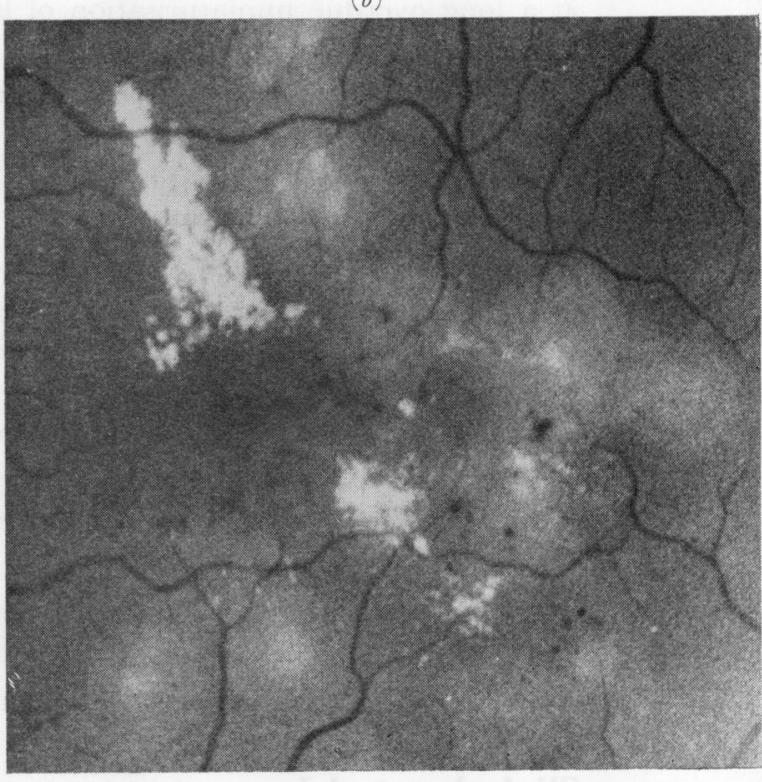

(c)

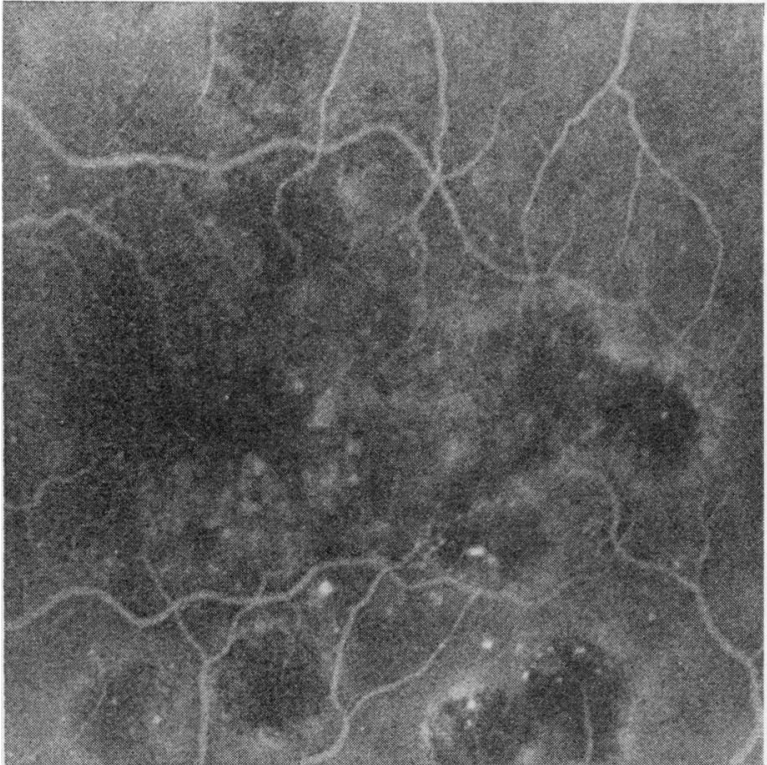

FIG. 4 Diabetic retinopathy with extensive leakage in the adjacent temporal area; (a) fluorogram of the late phase, before light coagulation, showing leaking vessels, (b) monochrome, 2 weeks after light $\overrightarrow{0}$ coagulation, showing circinate rings and coagulation scars, (c) fluorogram 2 weeks after light coagulation. Aperture $2^{\circ}$, power 6, exposure I $5 \mathrm{sec}$.

was preferred. In the case of a malignant melanoma of the choroid aperture $3^{\circ}$, power 6 , and exposure time 2 sec. were used effectively (Fig. 5, opposite).

The average exposure time was $\mathrm{I} \cdot \mathrm{O}-\mathrm{I} \cdot 5 \mathrm{sec}$, and the maximum was 2 sec. The number of $\stackrel{\mathscr{Q}}{\rightarrow}$ applications required varied from three (cases of central serous retinopathy) to 202 (peripheral $\frac{0}{0}$

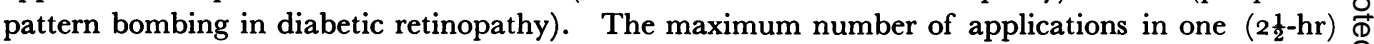
session was 320 (3 patients), with which the cooling system of the machine, although a little noisy, $\frac{\stackrel{\rho}{\mathbb{P}}}{\mathrm{O}}$ seemed to cope adequately. A total of 1,482 applications has been made with the machine without technical difficulties. 


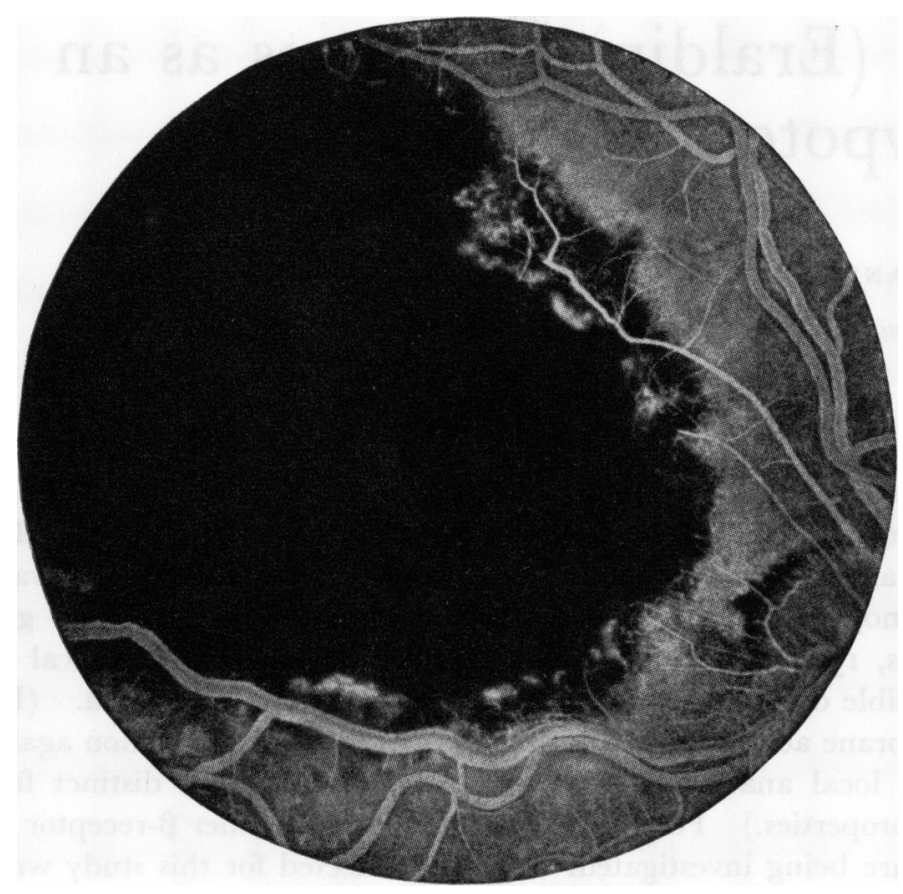

FIG. 5 Fluorogram. Malignant melanoma of the choroid treated with $O$ 'Malley instrument. Aperture $3^{\circ}$, power 6, exposure 2 sec.

\section{Conclusions}

There are several factors in favour of the O'Malley light coagulator as compared with the Oberkochen instrument:

(a) Much better manoeuvrability of the ophthalmoscope.

(b) The illumination of the fundus is more even than in the Zeiss instrument, where a very highly illuminated target focus affects the operator's light adaptation and makes the orientation in reference to the rest of the fundus very difficult, especially with small apertures.

(c) It was found that aperture $2^{\circ}$ was a more useful size than the choice between the apertures $1 \cdot 5^{\circ}$ or $3^{\circ}$ in the Zeiss coagulator when treating macular or paramacular lesions.

(d) The time pre-selectors and counting device, although not essential, were appreciated.

(e) The price is much lower.

At any selected aperture the power setting required for sufficient reactions left plenty in reserve. The power output is in the range of the green scale of the Zeiss machine but including the first setting of the red scale. More power may be necessary in cases of, e.g. hazy media or perhaps retinoblastoma, with which we had no experience in the present series. It is felt, however, that by prolonging the time of application an equivalent light energy would be delivered in such cases. 